\title{
What Is the Meaning of the Square Root of the Number Three in Biochemistry?
}

\author{
Tahir Ölmez \\ Social Sciences Dept., Selçuk University, Konya, Turkey \\ Email: bsonmez3@gmail.com, tolmez123@yahoo.com
}

How to cite this paper: Ölmez, T. (2021) What Is the Meaning of the Square Root of the Number Three in Biochemistry? Open Access Library Journal, 8: e7123. https://doi.org/10.4236/oalib.1107123

Received: December 29, 2020

Accepted: January 24, 2021

Published: January 27, 2021

Copyright $\odot 2021$ by author(s) and Open Access Library Inc.

This work is licensed under the Creative Commons Attribution International License (CC BY 4.0).

http://creativecommons.org/licenses/by/4.0/

\begin{abstract}
According to Quantum Perspective Model, this article researches whether there is a link between the square root of three numbers and the genetic codes. At first, when the digits of the square root of three numbers [1] after the comma are converted from decimal (10) number base system to binary (2) number base system, it corresponds to nucleotide bases. Secondly, the results obtained by this way are expressed as nucleotide bases (A, T, C, G, and U), (A) Adenine, (T) Thymine, (C) Cytosine, (G) Guanine, (U) Uracil. From this point of view, when the first three hundred and sixty digits of the square root of the two numbers after the comma are calculated, the gene sequence is obtained as follows: [GGATGACTACGGGTTTAGAAA]. Thirdly, the search result is similar to DENTICLE HERRING, after the NCBI (National Biotechnology Information Center) searched this sequence. Fourthly, the genetic codes of bony fish were found to be similar to human genetic codes. In summary, with these results, the link between the square root of three in mathematical science and the genetic codes in biochemistry was determined.
\end{abstract}

\section{Subject Areas}

Mathematics, Number Theory

\section{Keywords}

Quantum Perspective Model, Denticle Herring, Binary Number Base System, The Square Root of Three and NCBI (National Biotechnology Information Center)

\section{Introduction and Calculation of the Square Root of Three Numbers from Decimal Base System (10) to Binary Base System (2) and Binary Base System (2) to Decimal Base System (10)}

The relationships between numbers and genetic codes are not only researched 
with velocity of light numbers [2] but also researched with the golden ratio numbers, too [3]. The name of this relationship research is called Quantum Perspective Model by Kevser Köklü [4]. Then, the relationships between the square root of the number two and the genetic codes are researched by Tahir ÖLMEZ [5]. Now, as per this model, this paper attempts to search the relationships between the square root of the number three and the genetic codes (see Table 1).

\section{Methods and Discussion}

The chemical structures of bases include Carbon $(\mathbf{C})$, Nitrogen $(\mathbf{N})$, Oxygen $(\mathbf{O})$, and Hydrogen $(\mathrm{H})$. Calculation of bases with chemical atoms (See also Table 2) (Ölmez T, 2020) [3].

The atomic numbers of them: Carbon $(\mathbf{C}): 6$, Nitrogen $(\mathrm{N}): 7$, Oxygen $(\mathrm{O}): 8$, Hydrogen (H): 1 (Wieser E M et al., 2013) [6]. The chemical structures of bases (A, T, C, G, and U) are shown below (Ölmez T, 2020) [3].

Table 1. The representation of decimal numbers in the binary base and vice versa.

\begin{tabular}{|c|c|c|c|c|c|c|c|c|c|c|}
\hline DECIMAL & 1 & 2 & 3 & 4 & 5 & 6 & 7 & 8 & 9 & 10 \\
\hline$B I N A R Y$ & 01 & 10 & 11 & 100 & 101 & 110 & 111 & 1000 & 1001 & 1010 \\
\hline DECIMAL & 11 & 12 & 13 & 14 & 15 & 16 & 17 & 18 & 19 & 20 \\
\hline$B I N A R Y$ & 1011 & 1100 & 1101 & 1110 & 1111 & 10000 & 10001 & 10010 & 10011 & 10100 \\
\hline DECIMAL & 21 & 22 & 23 & 24 & 25 & 26 & 27 & 28 & 29 & 30 \\
\hline$B I N A R Y$ & 10101 & 10110 & 10111 & 11000 & 11001 & 11010 & 11011 & 11100 & 11101 & 11110 \\
\hline DECIMAL & 31 & 32 & 33 & 34 & 35 & 36 & 37 & 38 & 39 & 40 \\
\hline$B I N A R Y$ & 11111 & 100000 & 100001 & 100010 & 100011 & 100100 & 100101 & 100110 & 100111 & 101000 \\
\hline DECIMAL & 41 & 42 & 43 & 44 & 45 & 46 & 47 & 48 & 49 & 50 \\
\hline$B I N A R Y$ & 101001 & 101010 & 101011 & 101100 & 101101 & 101110 & 101111 & 110000 & 110001 & 110010 \\
\hline DECIMAL & 51 & 52 & 53 & 54 & 55 & 56 & 57 & 58 & 59 & 60 \\
\hline BINARY & 110011 & 110100 & 110101 & 110110 & 110111 & 111000 & 111001 & 111010 & 111011 & 111100 \\
\hline DECIMAL & 61 & 62 & 63 & 64 & 65 & 66 & 67 & 68 & 69 & 70 \\
\hline$B I N A R Y$ & 111101 & 111110 & 111111 & 1000000 & 1000001 & 1000010 & 100011 & 1000100 & 1000101 & 1000110 \\
\hline DECIMAL & 71 & 72 & 73 & 74 & 75 & 76 & 77 & 78 & 79 & 80 \\
\hline BINARY & 1000111 & 1001000 & 1001001 & 1001010 & 1001011 & 1001100 & 1001101 & 1001110 & 1001111 & 1010001 \\
\hline DECIMAL & 81 & 82 & 83 & 84 & 85 & 86 & 87 & 88 & 89 & 90 \\
\hline$B I N A R Y$ & 1010001 & 1010010 & 1010011 & 1010100 & 1010101 & 1010110 & 1010111 & 1011000 & 1011001 & 1011010 \\
\hline DECIMAL & 91 & 92 & 93 & 94 & 95 & 96 & 97 & 98 & 99 & 100 \\
\hline$B I N A R Y$ & 1011011 & 1011100 & 1011101 & 1011110 & 1011111 & 1100000 & 1100001 & 1100010 & 1100011 & 1100100 \\
\hline
\end{tabular}

Table 2. Representation of nucleotide bases (A, T, C, G and U) in chemical atoms.

\begin{tabular}{cccccc}
\hline ATOMS/NUCLEOTIDE BASES & $\boldsymbol{C}=\boldsymbol{6}$ & $\boldsymbol{H}=\mathbf{1}$ & $\boldsymbol{O}=\boldsymbol{8}$ & $\boldsymbol{N}=\mathbf{7}$ & \multicolumn{1}{c}{$\boldsymbol{S U M}$} \\
\hline ADENINE: $\mathrm{C}_{5} \mathrm{H}_{5} \mathrm{~N}_{5}$ & 5 & 5 & - & 5 & 70 \\
THYMINE: $\mathrm{C}_{5} \mathrm{H}_{6} \mathrm{~N}_{2} \mathrm{O}_{2}$ & 5 & 6 & 2 & 2 & 66 \\
CYTOSINE: $\mathrm{C}_{4} \mathrm{H}_{5} \mathrm{~N}_{3} \mathrm{O}_{1}$ & 4 & 5 & 1 & 3 & 64 \\
GUANINE: $\mathrm{C}_{5} \mathrm{H}_{5} \mathrm{~N}_{5} \mathrm{O}_{1}$ & 5 & 5 & 1 & 5 & 78 \\
URACIL: $\mathrm{C}_{4} \mathrm{H}_{4} \mathrm{~N}_{2} \mathrm{O}_{2}$ & 4 & 4 & 2 & 2 & 58 \\
\hline
\end{tabular}



(A) Adenine: $\mathrm{C}_{5} \mathrm{H}_{5} \mathrm{~N}_{5}: 70$;
(T) Thymine: $\mathrm{C}_{5} \mathrm{H}_{6} \mathrm{~N}_{2} \mathrm{O}_{2}: 66$,
(C) Cytosine: $\mathrm{C}_{4} \mathrm{H}_{5} \mathrm{~N}_{3} \mathrm{O}_{1}: 64$,
(G) Guanine: $\mathrm{C}_{5} \mathrm{H}_{5} \mathrm{~N}_{5} \mathrm{O}_{1}: 78$, and
(U) Uracil: $\mathrm{C}_{4} \mathrm{H}_{4} \mathrm{~N}_{2} \mathrm{O}_{2}: 58$
(Lodish $\mathrm{H}$ et al., 2018) [7].

Before this work, the fourteen group of Pi number can be shown as: Continuous UTA's by Kevser Köklü [4]. Secondly, another favorite sample of this research is done with velocity of light numbers by Kevser Köklü again [2]. This relationship between the numbers and genetic codes is called Quantum Perspective Model by Kevser Köklü [4]. Thirdly, in another article with identical cis regulatory elements examined the links between the Golden Ratio numbers [3]. Fourthly, there is a connection between Euler numbers and the Fibonacci series. When the numbers of Euler after the comma were converted from a decimal (10) number-based system to a binary (2) number-based system, they corresponded to the number " 55 " in the Fibonacci series [2]. Fifthly, there is a link between the square root of two [5] and the genetic codes. This can be shown as: [GGATGTCTATTGAGTGACAA] [5]. After all these studies, the square root of the number three and the genetic codes are now being investigated in relation to the Quantum Perspective Model.

\section{Calculation of the Square Root of Three Numbers and Genetic Codes}

The first two hundred digits of the square root of three [1] after the comma are here:

The square root of three $=$

1.732050807568877293527446341505872366942805253810380628055806979 4519330169088000370811461867572485756756261414154067030299699450 $\mathbf{9 4 9 9 8 9 5 2 4 7 8 8 1 1 6 5 5 5 1 2 0 9 4 3 7 3 6 4 8 5 2 8 0 9 3 2 3 1 9 0 2 3 0 5 5 8 2 0 6 7 9 7 4 8 2 0 1 0 1 0 8 4 6 7}$ 4923265015312343266903322886650672254668921837971227047131660367 $\mathbf{8 6 1 5 8 8 0 1 9 0 4 9 9 8 6 5 3 7 3 7 9 8 5 9 3 8 9 4 6 7 6 5 0 3 4 7 5 0 6 5 7 6 0 5 0 7 5 6 6 1 8 3 4 8 1 2 9 6 0 6 1 0 0 9}$ 4760218

At first, the first two digits after the comma were taken each time. For example, $73,20,50,80,75,68,87,72 \ldots$ and so on. Then these numbers are found in the binary number system in Table 1 . (For instance, "73", 1001001 and so on). Secondly, convert these binary numbers to decimal number base (For instance, “73" 1001001; $100=4,100=4$ and $1=1)$. Thirdly, all decimal numbers are subjected to the addition process, respectively. $(4+4+1=6)$. All of the first result of the addition is "77". Just like as in Guanine (G): 78 (See also Table 1).

\begin{tabular}{llllllll}
\hline $\mathbf{7 3}$ & $\mathbf{2 0}$ & $\mathbf{5 0}$ & $\mathbf{8 0}$ & $\mathbf{7 5}$ & $\mathbf{6 8}$ & $\mathbf{8 7}$ & $\mathbf{7 2}$ \\
1001001 & 10100 & 110010 & 1010001 & 1001011 & 1000100 & 1010111 & 1001000 \\
1001001 & 10100 & 110010 & 1010001 & 1001011 & 1000100 & 1010111 & 1001000 \\
$4+4+1$ & $+2+4$ & $+1+4+2$ & $2+8+1$ & $+4+2+3$ & $8+4$ & $2+2+7$ & $+4+8=\mathbf{7 7}$ (G) Guanine: 78
\end{tabular}




\section{Continued}

\begin{tabular}{|c|c|c|c|c|c|c|c|c|c|c|}
\hline 93 & 52 & 74 & 46 & 34 & 15 & 05 & 87 & \multicolumn{3}{|l|}{23} \\
\hline 1011101 & 110100 & 1001010 & 101110 & 100010 & 1111 & 101 & 1010111 & \multicolumn{3}{|l|}{10111} \\
\hline 1011101 & 110100 & 1001010 & 101110 & 100010 & 1111 & 101 & 1010111 & \multicolumn{3}{|l|}{10111} \\
\hline $2+3+5$ & $+6+4$ & $+4+2+2$ & $2+3+2$ & $+8+2$ & $+3+3$ & $2+1$ & $2+2+7$ & \multicolumn{3}{|c|}{$2+7=77(\mathbf{G})$ Guanine: $\mathbf{7 8}$} \\
\hline 66 & 94 & 28 & 05 & 25 & 38 & 10 & 38 & 06 & 28 & 05 \\
\hline 1000010 & 1011110 & 11100 & 101 & 11001 & 100110 & 1010 & 100110 & 110 & 11100 & 101 \\
\hline 1000010 & 1011110 & 11100 & 101 & 11001 & 100110 & 1010 & 100110 & 110 & 11100 & 101 \\
\hline$+16+2$ & $+5+3+2$ & $+3+4$ & $+2+1$ & $+1+2+1$ & $+4+6$ & $2+2$ & $2+1+$ & $2+1+2$ & $+3+4$ & $+2+1=7$ \\
\hline
\end{tabular}

\begin{tabular}{|c|c|c|c|c|c|c|c|c|}
\hline 58 & 06 & 97 & 94 & 51 & 93 & \multicolumn{3}{|l|}{30} \\
\hline 111010 & 110 & 1100001 & 1011110 & 110011 & 1011101 & \multicolumn{3}{|l|}{11110} \\
\hline 111010 & 110 & 1100001 & 1011110 & 110011 & 1011101 & \multicolumn{3}{|l|}{11110} \\
\hline 16 & 90 & 88 & 00 & 03 & 70 & 81 & 14 & 61 \\
\hline 16 & $+2+6+2$ & $+5+8$ & $+0+$ & 3 & $+8+6$ & $+2+8+1$ & $+3+2$ & $+3=76(\mathrm{G})$ Guanine: 78 \\
\hline 61(MORE) & 86 & 75 & 72 & 48 & 57 & \multicolumn{3}{|l|}{56} \\
\hline 111101 & 1010110 & 1001011 & 1001000 & 110000 & 111001 & \multicolumn{3}{|l|}{111000} \\
\hline 75 & 62 & 61 & 41 & 41 & 54 & 06 & \multicolumn{2}{|c|}{70} \\
\hline 1001011 & 111110 & 111101 & 101001 & 101001 & 110110 & 110 & \multicolumn{2}{|c|}{1000110} \\
\hline 1001011 & 111110 & 111101 & 101001 & 101001 & 110110 & 110 & \multicolumn{2}{|c|}{1000110} \\
\hline$+4+2+3$ & $+3+3+2$ & $+3+3+1$ & $+2+4+1$ & $+2+4+1$ & $+3+1+2$ & $+1+2$ & \multicolumn{2}{|c|}{$+8+6=62(\mathrm{C})$ Cytosine: 64} \\
\hline
\end{tabular}

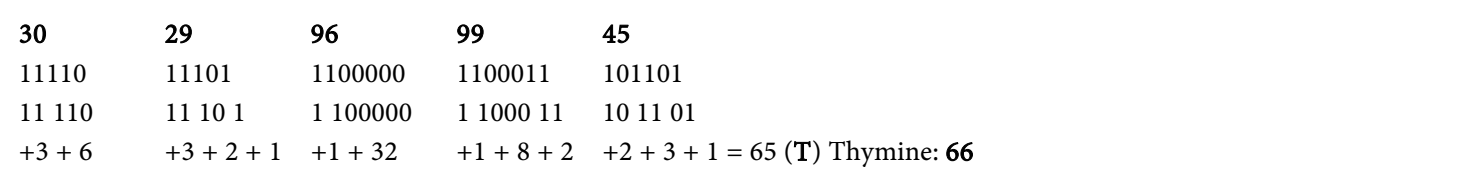

$\begin{array}{llllllll}09 & \mathbf{4 9} & \mathbf{9 8} & \mathbf{9 5} & \mathbf{2 4} & \mathbf{7 8} & \mathbf{8 1} \\ 1001 & 110001 & 1100010 & 1011111 & 11000 & 1001110 & 1010001 & \\ 1001 & 110001 & 1100010 & 1011111 & 11000 & 1001110 & 1010001 & \\ 2+1 & +1+8+1 & +1+8+2 & 2+3+3+1+1+8 & +4+3+2 & +2+17=70 \text { (A) Adenine: } 70 \\ 16 & \mathbf{5 5} & \mathbf{5 1} & \mathbf{2 0} & \mathbf{9 4} & \mathbf{3 7} & \mathbf{3 6} & \mathbf{4 8} \\ 10000 & 110111 & 110011 & 10100 & 1011110 & 100101 & 100100 & 110000 \\ 10000 & 110111 & 110011 & 10100 & 1011110 & 100101 & 100100 & 1 \\ 16 & +6+7 & +1+4+3 & +2+4 & +2+3+6 & +4+1+1 & +4+4 & 1=69 \text { (A) Adenine: } 70\end{array}$

\begin{tabular}{|c|c|c|c|c|c|c|c|c|c|c|c|}
\hline 48(MORE) & 52 & 80 & 93 & 23 & 19 & 02 & & & & & \\
\hline 110000 & 110100 & 1010001 & 1011101 & 10111 & 10011 & 10 & & & & & \\
\hline 10000 & 110100 & 1010001 & 1011101 & 10111 & 10011 & 10 & & & & & \\
\hline 16 & $+6+4$ & $+2+8+1$ & $+2+3+5$ & $+2+7$ & $+4+3+$ & $2=64(\mathrm{C})$ & Cytos & le: 64 & & & \\
\hline 30 & 55 & 82 & 06 & 79 & 74 & 82 & 01 & 01 & 08 & 46 & 74 \\
\hline 11110 & 110111 & 1010010 & 110 & 1001111 & 1001010 & 1010010 & 01 & 01 & 1000 & 101110 & 1001010 \\
\hline 11110 & 110111 & 1010010 & 110 & 1001111 & 1001010 & 1010010 & 01 & 01 & 1000 & 101110 & 10 \\
\hline $3+1+2$ & $+6+7$ & $+2+4+2$ & $+1+2$ & $+6+3+3$ & $+4+2+2$ & $+2+4+2$ & 1 & 1 & 8 & $2+3+2$ & $+4=77$ \\
\hline
\end{tabular}

(G) Guanine: 78 


\section{Continued}

\begin{tabular}{|c|c|c|c|c|c|c|c|c|}
\hline 74 & 92 & 32 & 65 & & & & & \\
\hline 1001010 & 1011100 & 100000 & 1000001 & & & & & \\
\hline 1010 & 1011100 & 100000 & 100000 & & & & & \\
\hline $2+2$ & $+5+1+4$ & 32 & $32=78(\mathrm{G})$ & Guanine: $\mathbf{7 8}$ & & & & \\
\hline 65(MORE) & 01 & 53 & 12 & 34 & 32 & \multicolumn{3}{|l|}{66} \\
\hline 1000001 & 01 & 110101 & 1100 & 100010 & 100000 & \multicolumn{3}{|l|}{1000010} \\
\hline 1 & 01 & 110101 & 1100 & 100010 & 100000 & \multicolumn{3}{|c|}{1000010} \\
\hline 1 & +1 & $+6+5$ & $+1+4$ & $8+2+$ & 32 & \multicolumn{3}{|c|}{$+16+2=66(\mathrm{~T})$ Thymine: 66} \\
\hline 90 & 33 & 22 & 88 & \multicolumn{5}{|l|}{66} \\
\hline 1011010 & 100001 & 10110 & 1011000 & \multicolumn{5}{|l|}{1000010} \\
\hline 1011010 & 100001 & 10110 & 1011000 & \multicolumn{5}{|l|}{1000010} \\
\hline$+2+6+2$ & $+16+1$ & $+2+6$ & $+5+8$ & \multicolumn{5}{|c|}{$+16+2=66(\mathrm{~T})$ Thymine: 66} \\
\hline 50 & 67 & 22 & 54 & 66 & \multicolumn{4}{|l|}{89} \\
\hline 110010 & 100011 & 10110 & 110110 & 1000010 & \multicolumn{4}{|l|}{1011001} \\
\hline 110010 & 100011 & 10110 & 110110 & 1000010 & \multicolumn{4}{|c|}{1011001} \\
\hline$+1+4+2$ & $+16+3$ & $+2+6$ & $+3+1+2$ & $+16+2$ & \multicolumn{4}{|c|}{$+5+2+1=66(\mathrm{~T})$ Thymine: 66} \\
\hline 21 & 83 & 79 & 71 & 22 & \multicolumn{4}{|l|}{70} \\
\hline 10101 & 1010011 & 1001111 & 1000111 & 10110 & \multicolumn{4}{|l|}{1000110} \\
\hline 10101 & 1010011 & 1001111 & 1000111 & 10110 & \multicolumn{4}{|l|}{1000110} \\
\hline $2+5$ & $+2+4+3$ & $6+3+3$ & $+8+7+$ & $+2+6$ & \multicolumn{4}{|c|}{$+8+7=66(\mathrm{~T})$ Thymine: 66} \\
\hline 47 & 13 & 16 & 60 & 36 & 78 & 61 & 58 & \\
\hline 101111 & 1101 & 10000 & 111100 & 100100 & 1001110 & 111101 & 111010 & \\
\hline 101111 & 1101 & 10000 & 111100 & 100100 & 1001110 & 111101 & 111010 & \\
\hline $2+3+3$ & $+3+1$ & 16 & $+7+4$ & $4+4$ & $+4+3+2$ & $+3+3+1$ & $+3+2+2=$ & 70 (A) Adenine: 70 \\
\hline 80 & 19 & 04 & 99 & 86 & 53 & 73 & 79 & 85 \\
\hline 1010001 & 10011 & 100 & 1100011 & 1010110 & 110101 & 1001001 & 1001111 & 1010101 \\
\hline 1010001 & 10011 & 100 & 1100011 & 1010110 & 110101 & 1001001 & 1001111 & 1010101 \\
\hline $2+8+1$ & $+4+3$ & +4 & $+1+8+2$ & $+2+2+6$ & $+6+5$ & $+4+4+1$ & $6+3+3$ & $+2+2+5=78(\mathrm{G})$ Guanine: 78 \\
\hline 93 & 89 & 46 & 76 & 50 & 34 & 75 & 06 & \\
\hline 1011101 & 1011001 & 101110 & 1001100 & 110010 & 100010 & 1001011 & 110 & \\
\hline 1011101 & 1011001 & 101110 & 1001100 & 110010 & 100010 & 1001011 & 110 & \\
\hline $2+3+5$ & $+5+2+1$ & $2+3+2$ & $+4+12$ & $+1+4+2$ & $+8+2$ & $+4+2+3$ & $+1+2=70$ & (A) Adenine: 70 \\
\hline 57 & 60 & 50 & 75 & 66 & 18 & 34 & & \\
\hline 111001 & 111100 & 110010 & 1001011 & 1000010 & 10010 & 100010 & & \\
\hline 111001 & 111100 & 110010 & 1001011 & 1000010 & 10010 & 100010 & & \\
\hline $3+4+1$ & $+7+4$ & $1+4+2$ & $+4+2+3$ & $+16+2$ & $+4+2+$ & $+8+2=69$ & (A) Adenine & $: 70$ \\
\hline 81 & 29 & 60 & 61 & 00 & 94 & 76 & 02 & 18 \\
\hline 1010001 & 11101 & 111100 & 111101 & 0 & 1011110 & 1001100 & 10 & 10010 \\
\hline 1010001 & 11101 & 111100 & 111101 & 0 & 1011110 & 1001100 & 10 & 10010 \\
\hline $2+8+1$ & $3+2+1$ & $+7+4$ & $+2+2+1$ & 0 & $+2+3+6$ & $+4+12$ & +2 & $+4+2=68(\mathrm{~A})$ Adenine: 70 \\
\hline
\end{tabular}

This sequence can be shown as [GGATGACTACGGGTTTAGAAA]. Let me try to explain this sequence with the "Quantum Perspective Model." For example, The first groups of the square root of three after comma equal to Guanine (G): 77 with the lack of one "1" Hydrogen bond (H: 1). (Remember, See Table 2; Guanine (G): 78) This result may mean the sequence of the square root of three in groups [GGATGACTACGGGTTTAGAAA]. The fourth groups of 
the square root of three after the comma is regarded as Thymine (T) with the lack of one Hydrogen bond ( $\mathrm{H}:$ 1). (Remember, See Table 2; Thymine (T): 66) (Because the deviations in the calculation of the square root of three numbers can be derived from the Adenine (A) - Thymine (T) Hydrogen bonds because of Adenine (A) pairs with Thymine (T) by two hydrogen bonds. Cytosine (C) Guanine (G) pairs with by three hydrogen bonds [4]. The reason for the lack of hydrogen bonds: Hydrogen bonding is a very versatile attraction (Ölmez T, 2020) [3]. Hydrogen bonds are relatively weak and easily broken by increasing hardness (Farrell R E, 2010) [8].

\section{Results}

After searching the square root of the three numbers with the National Biotechnology Information Center (NCBI) databases, some conceptual relationships with bony fish can ultimately be found. Types of bony fishes are based on DENTICLE HERRING (See Figure 1). Types of other living creatures are Barber pole worm, human chromosome 15, golden spiny mouse and bacterium [9] (See Figure 2).

\begin{tabular}{|c|c|c|c|c|c|c|c|c|}
\hline Description & Common Name & $\begin{array}{l}\text { Max } \\
\text { Score } \\
\nabla\end{array}$ & $\begin{array}{l}\text { Total } \\
\text { Score } \\
\nabla\end{array}$ & $\begin{array}{l}\text { Query } \\
\text { Cover } \\
\text { v }\end{array}$ & $\begin{array}{c}E \\
\text { value } \\
\text { V }\end{array}$ & $\begin{array}{l}\text { Per. } \\
\text { Ident } \\
\nabla\end{array}$ & Acc. Len & Accession \\
\hline Denticeps clupeoides genome assembly, chromosome: 14 & denticle hering & 36.2 & 36.2 & $85 \%$ & 8.9 & $100.00 \%$ & 21670620 & LR535026.1 \\
\hline 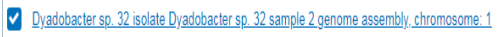 & Dyadobacter sp 32 & 34.2 & 34.2 & $80 \%$ & 35 & $100.00 \%$ & 7101228 & $\underline{\mathrm{LR} 735258.1}$ \\
\hline Prunus ducis DNA, unplaced-scaffodd 1126 & almond & 34.2 & 34.2 & $80 \%$ & 35 & $100.00 \%$ & 15750 & AP021463.1 \\
\hline Haemorchus contortus strain N2 H60 AP chromosome 1 & barber pole worm & 34.2 & 94.6 & $80 \%$ & 35 & $10000 \%$ & 83295456 & $\underline{C P 035005.1}$ \\
\hline - Complete annotated genome sequence of the bacterium Dyadobacter sp. 32 & Qyadobacter sp. 32 & 34.2 & 34.2 & $80 \%$ & 35 & $100.00 \%$ & 7101228 & $\underline{\text { LR732074.1 }}$ \\
\hline - Lactobacillus sp. 36.2020) chromosome, complete genome & Lactobacillus sp. 36(2020) & 34.2 & 34.2 & $80 \%$ & 35 & $100.00 \%$ & 2150664 & $\underline{\mathrm{CP} 047410.1}$ \\
\hline Avicola amphibius genome assembly: chromosome: 16 & Eurasian vater vole & 32.2 & 32.2 & $76 \%$ & 139 & $100.00 \%$ & 51382976 & $\underline{\text { LR062396.1 }}$ \\
\hline Gadus mohua genome assembly, chromosome: 19 & Allantic cod & 30.2 & 30.2 & $71 \%$ & 549 & $100.00 \%$ & 22015597 & L L6633961.1 \\
\hline - Homo sapiens DNA, chromosome 15 , nearly complete genome & $\underline{\text { human }}$ & 30.2 & 30.2 & $71 \%$ & 549 & $10000 \%$ & 95637968 & AP023475.1 \\
\hline Aconys russetus genome assembly, chromosome: 8 & golden spiny mouse & 30.2 & 30.2 & $71 \%$ & 549 & $100.00 \%$ & 77196262 & L LR877219.1 \\
\hline Escherchia coi istain RH-048-CS chromosome & Eschenchia coli & 30.2 & 30.2 & $71 \%$ & 549 & $100.00 \%$ & 7567896 & $\underline{\text { CP050205.1 }}$ \\
\hline$\checkmark$ Oscheius tipulae isolate CEW1 chromosome V & Oscheius tpulae & 30.2 & 30.2 & $71 \%$ & 549 & $100.00 \%$ & 10817478 & CP059032.1 \\
\hline Arabidopsis thal ana genome assembly. chromosome: 1 & thale cress & 30.2 & 30.2 & $71 \%$ & 549 & $100.00 \%$ & 30871806 & $\underline{\text { LR7978007.1 }}$ \\
\hline Arabidopsis thaliana genome assembly, chromosome: 1 & thale cress & 30.2 & 30.2 & $71 \%$ & 549 & $100.00 \%$ & 29915687 & $\underline{\text { LR7978002.1 }}$ \\
\hline Schistosoma mansoni strain Puerto Rico genome assembly chromosome: 3 & $\underline{\text { Schistosoma mansoni }}$ & 30.2 & 30.2 & $71 \%$ & 549 & $100.00 \%$ & 50458499 & $\underline{H E 601626.2}$ \\
\hline v schistosoma mansoni strain Puerto Rice genome assembly, chromosome: 2 & $\underline{\text { Schistosomamannsoni }}$ & 30.2 & 30.2 & $71 \%$ & 549 & $100.00 \%$ & 48130368 & HE601625.2 \\
\hline
\end{tabular}

Figure 1. The NCBI (National Biotechnology Information Center) result for nucleotide sequence "GGATGACTACGGGTTTAGAAA" [9].

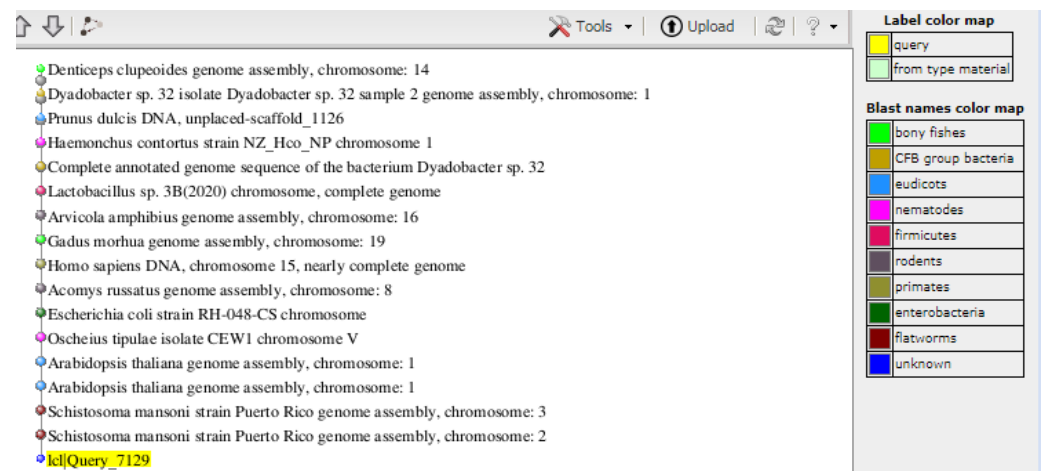

Figure 2. The NCBI (National Biotechnology Information Center) result blast tree view widget for "GGATGACTACGGGTTTAGAAA" nucleotide sequence [9]. 


\section{Conclusions}

Although the most widely used number digit system today is the decimal system, in this study, the square root of the number three is expressed as a binary number base system instead of a decimal base system [10]. When the numbers of Euler after the comma were converted from the decimal (10) number base system to the binary (2) number base system, they corresponded to the number " 55 " in the Fibonacci series $(0,1,1,2,3,5,8,13,21,34,55 \ldots)$ [11]. In the same way, the binary (2) number-based system was used in this research. The alphabet of DNA and RNA is associated with binary numbers [12]. However, almost all the studies so far into perception of irrational numbers have focused on numbers, on the other hands, future studies should be studied in detail later in the perspective of genetic codes.

Firstly, the result of this research can be summarized as the expression of the numbers of three roots after commas by chemical formulas in genetic codes. Secondly, both digits after the comma were thought to be an indicator of genetic codes. As a common feature of Biochemistry and Mathematical sciences, NCBI blasts are obtained. Because these results include both bony fish and especially DENTICLE HERRING. The common feature of pi numbers [4] and Euler numbers [13] along with the square of the speed of light is that the NCBI results are bony fish [2] [3]. Let alone this result, NCBI result for CAAT Box also consists of bony fishes, especially DENTICLE HERRING [3]. Denticle Herring is the most primitive living clupeiform [14]. Here is the consequence of how a single amino acid change on fish can have a major impact on ecological adaptation which is described [15]. Therefore, in the calculation of the golden ratio numbers, triplet codons were also used to express cis-regulatory elements (TATA Box, CAAT Box and GC box) [3]. Thirdly, with the genetic codes of the square root of two, the genetic codes of the square root of three consist of the same gene sequence in the following sequence: [GGATGACT] [5]. Finally, the results of calculating the square root of three numbers with genetic codes can be expressed by: [(A) Adenine, (T) Thymine, (C) Cytosine, (G) Guanine and (U) Uracil]. So, these can be associated with both Biochemistry and Mathematics. Namely, the square root numbers of the three after the comma can be attributed not only to numbers in mathematics, but also to genetic codes and chemical formulas in Biochemistry. In summary, researching this interesting connection in terms of the Quantum Perspective Model basically reveals the comparability of small units of analysis of the sciences, as in genetic codes and mathematical numbers.

\section{Conflicts of Interest}

The author declares no conflicts of interest regarding the publication of this paper.

\section{References}

[1] https://apod.nasa.gov/htmltest/gifcity/sqrt3.1mil 
[2] Köklü, K. (2019) Is Relativity Theory Also Valid in Biogenetics and Mathematics? NeuroQuantology, 17, 53-58. https://doi.org/10.14704/nq.2019.17.3.1999

[3] Ölmez, T. (2020) Is There an Aesthetics in Golden Ratio as Regards to the Common Cis-Regulatory Elements versus to Atomic Numbers of Elements with Respect to Quantum Perspective Model? Neurology and Neuroscience Reports, 3, 1-4.

[4] Köklü, K. (2019) A Quantum Perspective Model to Genetic Codes through Various Sciences. NeuroQuantology, 17, 15-18. https://doi.org/10.14704/nq.2019.17.3.1974

[5] Ölmez, T. (2021) According to the Binary Number Base System, Are the Square Roots of Two Numbers Also Significant in Biochemistry?

[6] Wieser, E.M., Holden, N., Coplen, B.T., Böhlke, J.K., Berglund, M., Brand, W.A., et al. (2013) Atomic Weights of the Elements 2011. Pure and Application Chemistry, 85, 1047-1078. https://doi.org/10.1351/PAC-REP-13-03-02

[7] Lodish, H., Berk, A., Zipursky, S.L., Matsudaira, P., Baltimore, D. and Darnell, J. (2018) Molecular Cell Biology. 6th Edition, Translation: Geçkil, H., Özmen, M., Yeşilada, Ö., Palme Publishing, New York, 294-302.

[8] Farrell, R.E. (2010) RNA Methodologies A Laboratory Guide for Isolation and Characterization. 4th Edition, Elsevier Academic Press, Amsterdam, 704-710.

[9] Basic Local Alignment Search Tool. https://blast.ncbi.nlm.nih.gov/Blast.cgi

[10] Brind, S. (2019) Alternative Number Systems: What Are Binary Numbers? https://owlcation.com/stem/Binary-Numbers

[11] Ölmez, T. (2021) Is There a Similarity between Fibonacci Sequence and Euler's Number with Respect to Quantum Perspective Model? Global Journal of Science Frontier Research, 20, 33. https://doi.org/10.34257/GJSFRFVOL20IS9PG35

[12] Sergey, P. (2019) The Genetic Code, Algebraic Codes and Double Numbers. https://doi.org/10.20944/preprints201911.0301.v1

[13] Ölmez, T. (2021) With Respect to Quantum Perspective Model, Can Euler Numbers Be Related to Biochemistry? Global Journal of Science Frontier Research, 20, 7-14. https://doi.org/10.34257/GISFRFVOL20IS9PG7

[14] https://www.britannica.com/animal/Denticipitidae

[15] Hill, J., et al. (2019) Recurrent Convergent Evolution at Amino Acid Residue 261 in Fish Rhodopsin. PNAS, 116, 18473-18478.

https://www.pnas.org/content/116/37/18473 